\title{
Synthesis, modification, and characterization of hyperbranched poly(ether ketones)
}

\author{
C.-F. Shu* , C.-M. Leu, F.-Y. Huang \\ Department of Applied Chemistry, National Chiao Tung University, Hsin-Chu 30035, Taiwan
}

Received 30 September 1998; received in revised form 4 December 1998; accepted 21 December 1998

\begin{abstract}
This report presents the synthesis and chemical modification of hyperbranched poly(ether ketones). The polymer was conveniently prepared by direct polycondensation of an $\mathrm{AB}_{2}$ monomer, 3,5-diphenoxybenzoic acid, using phosphorus pentoxide/methanesulfonic acid (PPMA) as the condensing agent and solvent. The hyperbranched poly(ether ketone) could be modified via the electrophilic aromatic substitution of the active phenoxy groups at the chain ends with a variety of carboxylic acids. The thermal properties of the hyperbranched poly(ether ketones) depend heavily on the nature of the chain end, with glass transition temperature ranging from $-24^{\circ} \mathrm{C}$ to $180^{\circ} \mathrm{C}$. Moreover, the length of the terminal alkyl groups significantly influences the solubility of the hyperbranched poly(ether ketones). By varying the chain ends, hyperbranched poly(ether ketones) soluble in either a polar or nonpolar solvent could be obtained. (C) 1999 Elsevier Science Ltd. All rights reserved.
\end{abstract}

Keywords: Electrophilic aromatic substitution; Glass transition temperature; Hyperbranched poly(ether ketone)

\section{Introduction}

In recent years, nonlinear polymers such as dendritic or hyperbranched macromolecules have attracted considerable attention owing to the potential new properties of their highly branched, highly functionalized, three-dimension globular structure [1,2]. Dendrimers which have a welldefined and perfectly branching structure are built up by either a stepwise divergent or a convergent approach [36]. The sequential synthetic scheme frequently involves isolating and purifying the product at every step of the growth process, thereby limiting the large scale preparation. As an alternative, hyperbranched polymers are prepared by a one-step polymerization process that yields a highly branched, irregular structure. Although having a less perfect structure than dendrimers, hyperbranched polymers still maintain many of the architectural features found in their more perfectly defined dendritic counterparts and are supposed to exhibit properties resembling those of dendritic ones [7].

The one-step synthesis allows hyperbranched polymers to be more readily available and prepared on a large scale for potential applications. This attractive feature has led to the

\footnotetext{
*Corresponding author. Tel.: 00886-35-71212156544; fax: 00886-35723764.

E-mail address: shu@cc.nctu.edu.tw (C.-F. Shu)
}

development of novel synthetic routes for the preparation of hyperbranched polymers [8-36], especially the one-step synthesis based on $\mathrm{AB}_{2}$ monomers which have $\mathrm{A}$ and $2 \mathrm{~B}$ functional groups located at $1,3,5$ positions of a benzene ring. This report concerns the use of an $\mathrm{AB}_{2}$ monomer, 3,5diphenyoxybenzoic acid, in the one-step preparation of a hyperbranched poly(ether ketone). Two methods were used to prepare traditional linear poly(ether ketones) [37, 38]. The first method is a synthesis involving nucleophilic aromatic substitution, resulting in the formation of an aryl ether linkage. The second method is a synthesis involving electrophilic aromatic substitution in which an aryl ketone linkage is obtained. The nucleophilic reaction was applied to synthesise hyperbranched/dendritic poly(ether ketones) using $\mathrm{AB}_{2}$ monomers containing a phenolic group and two aryl fluorides which were activated toward nucleophilic displacement by carbonyl moieties [16,35,39]. The synthetic procedure used herein is derived from the electrophilic substitution reaction developed by Ueda to prepare linear aromatic poly(ether ketones) [40-42]. In this procedure, the polymeric aryl ketone linkages are formed via direct self-polycondensation of the substituted benzoic acid containing phenyl ether structures using a mixture of phosphorus pentoxide/methanesulfonic acid (PPMA) as the condensing agent and solvent [40-43]. This one-step synthesis leads to the formation of a hyperbranched poly(ether ketone). This polymer could be derivatized by reacting the 
terminal phenoxy groups with various carboxylic acids. The physical properties of these hyperbranched poly(ether ketones) are investigated, along with the effect of changes in the nature of the chain ends which are evaluated as well.

\section{Experimental section}

\subsection{General directions}

The reagent PPMA (Eaton's reagent) was obtained from Aldrich and used as received. Other starting materials and reagents were used as obtained from the suppliers. Nuclear magnetic resonance (NMR) spectra were recorded on a Varian Unity $300 \mathrm{MHz}$ spectrometer. Differential scanning calorimetry (DSC) was performed on a SEIKO SSC 5200 DSC using a heating/cooling rate of $10^{\circ} \mathrm{C} \mathrm{min}{ }^{-1}$. Thermogravimetric analysis (TGA) was made on a SEIKO TG/ DTA 200 using a heating rate of $10^{\circ} \mathrm{C} \mathrm{min}^{-1}$ in nitrogen. Size-exclusion chromatography (SEC) was carried out on a Waters chromatography connected to a waters 410 differential refractometer with DMF as the solvent. UV-VIS absorption spectra were taken on a HP 8453 UV/VIS spectrometer. Infrared spectra were recorded on a Nicolet 520 FTIR spectrometer. Mass spectra were obtained on a JEOL JMS-HX 110 with EI ionization. Analytical TLC was performed on commercial Merck plate coated with silica gel GF254. Silica gel for column chromatography was Merck kieselgel 60 (70-230 mesh).

\subsection{1-Methyl-3,5-diphenoxybenzene (1)}

\subsubsection{Method A}

A mixture of phenol $(9.04 \mathrm{~g}, 96.1 \mathrm{mmol}), \mathrm{KOH}(4.4 \mathrm{~g}$, $80.0 \mathrm{mmol})$, and toluene $(6 \mathrm{ml})$ was stirred at $145^{\circ} \mathrm{C}$ for $4 \mathrm{~h}$ with water being collected in a Dean-Stark trap. Excess phenol and water were then removed under reduced pressure at $160^{\circ} \mathrm{C}$ for $2 \mathrm{~h}$. To the dry salt was added copper powder $(0.1 \mathrm{~g}), 3,5$-dibromotoluene $(2.0 \mathrm{~g}, 8.0 \mathrm{mmol})$, and phenol ( $4 \mathrm{ml})$. The reaction mixture was stirred under nitrogen at $210^{\circ} \mathrm{C}$ for $3 \mathrm{~h}$. The reaction mixture was poured into water $(150 \mathrm{ml})$, and $5 \mathrm{wt} . \% \mathrm{NaOH}$ aqueous solution was added to dissolve the excess phenol. The mixture was extracted with ethyl acetate $(3 \times 70 \mathrm{ml})$. The combined extracts were dried and evaporated to dryness. The crude product was purified by column chromatography, eluting with $\mathrm{CH}_{2} \mathrm{Cl}_{2} /$ hexane $1: 2$ to give $1(2.08 \mathrm{~g}, 94 \%)$ as a colorless liquid.

\subsubsection{Method B}

A mixture of 5-methylresorcinol (10 g, $80.6 \mathrm{mmol}), \mathrm{KOH}$ $(9.04 \mathrm{~g}, 161.1 \mathrm{mmol})$, and toluene $(150 \mathrm{ml})$ was stirred at $145^{\circ} \mathrm{C}$ for $4 \mathrm{~h}$ with water being collected in a Dean-Stark trap. The solvent and water were then removed under reduced pressure at $160^{\circ} \mathrm{C}$ for $2 \mathrm{~h}$. To the dry salt was added bromobenzene (63 g, $400 \mathrm{mmol}), \mathrm{CuCl}(3 \mathrm{~g})$, and pyridine $(160 \mathrm{ml})$. The mixture was stirred under nitrogen at $140^{\circ} \mathrm{C}$ for $15 \mathrm{~h}$. The reaction mixture was poured into water $(500 \mathrm{ml})$, acidified with $4 \mathrm{~N} \mathrm{HCl}_{\mathrm{aq}}$, and extracted with ethyl acetate $(3 \times 250 \mathrm{ml})$. The combined extracts were dried and evaporated to dryness. The crude product was purified by column chromatography, eluting with $\mathrm{CH}_{2} \mathrm{Cl}_{2}$ /hexane $1: 2$ to give $1(15.81 \mathrm{~g}, 71 \%)$. ${ }^{1} \mathrm{H}$ NMR $\left(\mathrm{CDCl}_{3}\right) \delta 2.26(\mathrm{~s}, 3 \mathrm{H}), 6.48(\mathrm{t}, 1 \mathrm{H}, J=2.4 \mathrm{~Hz}), 6.53$ $(\mathrm{d}, 2 \mathrm{H}, J=2.4 \mathrm{~Hz}), 7.01(\mathrm{~d}, 4 \mathrm{H}, J=8.4 \mathrm{~Hz}), 7.09$ (t, 2 $\mathrm{H}, J=7.2 \mathrm{~Hz}), 7.32(\mathrm{dd}, 4 \mathrm{H}, J=8.4,7.2 \mathrm{~Hz}) ;{ }^{13} \mathrm{C} \mathrm{NMR}$ $\left(\mathrm{CDCl}_{3}\right) \delta 21.5,106.5,114.0,119.1,123.4,129.7,141.0$, 156.8, 158.4; $\mathrm{MS}(m / e)$ 276.1150, calcd. 276.1150 for $\mathrm{C}_{19}$ $\mathrm{H}_{16} \mathrm{O}_{2}$.

\subsection{3,5-Diphenoxybenzoic acid (2)}

To a mixture of $1(12.0 \mathrm{~g}, 43.4 \mathrm{mmol})$, water $(6 \mathrm{ml})$, and pyridine $(160 \mathrm{ml})$ heated at $100^{\circ} \mathrm{C}, \mathrm{KMnO}_{4}(68 \mathrm{~g}$, $0.43 \mathrm{mmol}$ ) was added in small portions over $6 \mathrm{~h}$. The reaction mixture was stirred at $120^{\circ} \mathrm{C}$ for $36 \mathrm{~h}$. The manganese dioxide was filtered and extracted with hot water, and the filtrate was acidified with $4 \mathrm{~N} \mathrm{HCl}_{(\mathrm{aq})}$. The product was collected by filtration and purified by column chromatography, eluting with $\mathrm{CHCl}_{3}$ and then ethyl acetate to give 2 (10.65 g, 80\%). ${ }^{1} \mathrm{H}$ NMR (D6-DMSO) $\delta 6.90(\mathrm{t}, 1 \mathrm{H}, J=$ $2.4 \mathrm{~Hz}), 7.10(\mathrm{~d}, 4 \mathrm{H}, J=8.4 \mathrm{~Hz}), 7.12(\mathrm{~d}, 2 \mathrm{H}, J=2.4 \mathrm{~Hz})$, $7.21(\mathrm{t}, 2 \mathrm{H}, J=7.2 \mathrm{~Hz}), 7.44(\mathrm{dd}, 4 \mathrm{H}, J=8.4,7.2 \mathrm{~Hz})$, 13.29 (br, $1 \mathrm{H}) ;{ }^{13} \mathrm{C}$ NMR (D6-DMSO) $\delta$ 112.1, 112.4, $119.7,124.6,130.3,133.8,155.4,158.7,166.1$; MS (m/e) 306.0870, calcd. 306.0892 for $\mathrm{C}_{19} \mathrm{H}_{14} \mathrm{O}_{4}$.

\subsection{Methyl 3,5-diphenoxybenzoate (3)}

A mixture of $2(0.15 \mathrm{~g}, 0.49 \mathrm{mmol})$, methanol $(4 \mathrm{ml})$ and concentrated $\mathrm{H}_{2} \mathrm{SO}_{4}(0.2 \mathrm{ml})$ was heated at reflux for $3 \mathrm{~h}$. The reaction mixture was poured into water $(150 \mathrm{ml})$, neutralized with aqueous sodium bicarbonate solution, and extracted with ethyl acetate $(3 \times 30 \mathrm{ml})$. The combined extracts were dried and evaporated to dryness to give 3 $(0.152 \mathrm{~g}, 97 \%) .{ }^{1} \mathrm{H}$ NMR $\left(\mathrm{CDCl}_{3}\right) \delta 3.83(\mathrm{~s}, 3 \mathrm{H}), 6.86(\mathrm{t}$, $1 \mathrm{H}, J=2.1 \mathrm{~Hz}), 7.02(\mathrm{~d}, 4 \mathrm{H}, J=8.7 \mathrm{~Hz}), 7.13(\mathrm{t}, 2 \mathrm{H}, J=$ $7.8 \mathrm{~Hz}), 7.34$ (d, $2 \mathrm{H}, J=2.1 \mathrm{~Hz}), 7.35(\mathrm{dd}, 4 \mathrm{H}, J=8.7$, $7.8 \mathrm{~Hz}) ;{ }^{13} \mathrm{C} \mathrm{NMR}\left(\mathrm{CDCl}_{3}\right) \delta 52.3,113.3,113.8,119.3$, $124.0,129.9,132.7,156.1,158.7,166.0 ; \mathrm{MS}(m / e)$ 320.1044, calcd. 320.1049 for $\mathrm{C}_{20} \mathrm{H}_{16} \mathrm{O}_{4}$.

\subsection{Methyl 3,5-di(4-benzoylphenoxy)benzoate (4)}

A mixture of $3(0.2 \mathrm{~g}, 0.624 \mathrm{mmol})$, benzoic acid $(0.47 \mathrm{~g}$, $3.85 \mathrm{mmol})$, and PPMA $(3.5 \mathrm{ml})$ was stirred under nitrogen at $80^{\circ} \mathrm{C}$ for $4 \mathrm{~h}$. The reaction mixture was poured into water $(200 \mathrm{ml})$, neutralized with sodium bicarbonate, and extracted with ethyl acetate $(3 \times 50 \mathrm{ml})$. The combined extracts were dried over anhydrous sodium sulfate, and evaporated to dryness to give $4(0.32 \mathrm{~g}, 97 \%)$. ${ }^{1} \mathrm{H}$ NMR $\left(\mathrm{CDCl}_{3}\right) \delta 3.88(\mathrm{~s}, 3 \mathrm{H}), 7.02(\mathrm{t}, 1 \mathrm{H}, J=2.4 \mathrm{~Hz}), 7.08$ $(\mathrm{d}, 4 \mathrm{H}, J=8.7 \mathrm{~Hz}), 7.47(\mathrm{dd}, 4 \mathrm{H}, J=7.5,7.2 \mathrm{~Hz}), 7.53$ $(\mathrm{d}, 2 \mathrm{H}, J=2.4 \mathrm{~Hz}), 7.57(\mathrm{t}, 2 \mathrm{H}, J=7.2 \mathrm{~Hz}), 7.77(\mathrm{~d}, 4 \mathrm{H}$, 


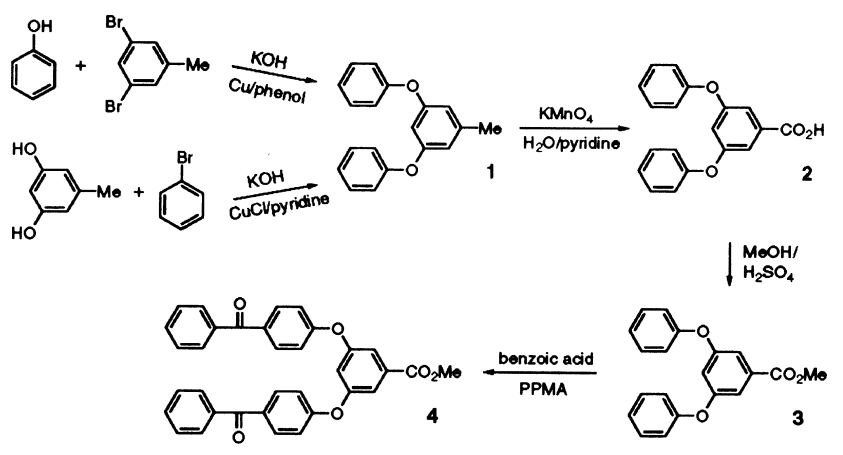

Scheme 1.

$J=7.5 \mathrm{~Hz}), 7.84(\mathrm{~d}, 4 \mathrm{H}, J=8.7 \mathrm{~Hz}) ;{ }^{13} \mathrm{C} \mathrm{NMR}\left(\mathrm{CDCl}_{3}\right) \delta$ 52.5, 115.5, 116.1, 117.9, 128.3, 129.8, 132.3, 132.6, 133.0, $133.4,137.6,157.3,160.1,165.5,195.3 ; \mathrm{MS}(\mathrm{m} / \mathrm{e})$ 528.1539, calcd. 528.1573 for $\mathrm{C}_{34} \mathrm{H}_{24} \mathrm{O}_{6}$.

\subsection{Preparation of hyperbranched poly(ether ketone) (P1)}

A solution of $2(0.6 \mathrm{~g})$ in PPMA $(3.6 \mathrm{ml})$ was stirred under nitrogen at $90^{\circ} \mathrm{C}$ for $24 \mathrm{~h}$. The reaction mixture was poured into water $(200 \mathrm{ml})$. The polymer was collected, washed with water, and stirred again in water $(200 \mathrm{ml})$ at $70^{\circ} \mathrm{C}$ for $12 \mathrm{~h}$. The polymer was collected and dried in
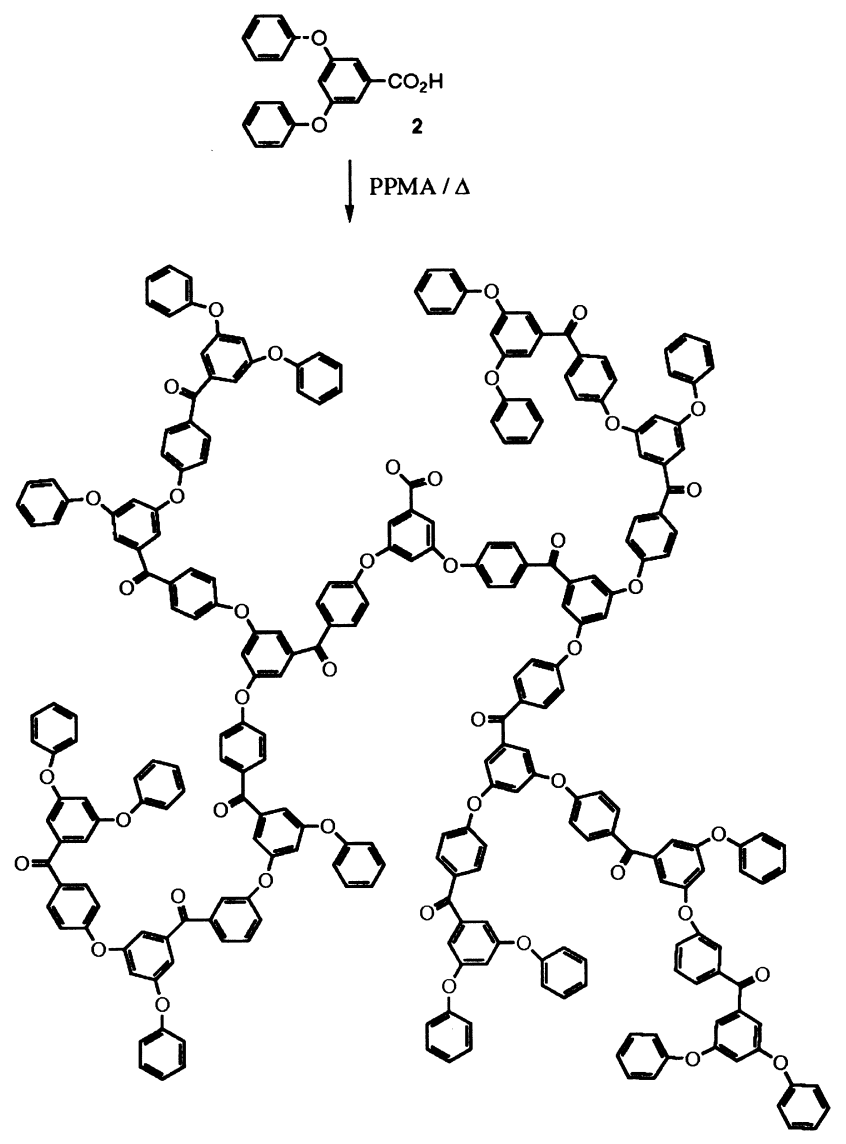

Scheme 2. vacuo. The crude product was purified by precipitating from $\mathrm{CH}_{2} \mathrm{Cl}_{2}$ into methanol to give $\mathbf{P 1}(0.5 \mathrm{~g}, 89 \%)$. Anal. Calcd. for $\mathrm{C}_{19} \mathrm{H}_{12} \mathrm{O}_{3}$ : C, 79.16; H, 4.20. Found: C, 77.70; H, 4.19 .

\subsection{Preparation of hyperbranched poly(ether ketone) (P2)}

A solution of P1 $(0.1 \mathrm{~g})$ and $p$-toluic acid $(0.66 \mathrm{~g})$ in PPMA $(3 \mathrm{ml})$ was heated at $90^{\circ} \mathrm{C}$ for $6 \mathrm{~h}$. The resulting solution was poured into water $(300 \mathrm{ml})$. The precipitate was filtered, and washed with water and methanol, and reprecipitated from DMF into methanol to give P2 (0.12 g, 87\%).

\subsection{Preparation of hyperbranched poly(ether ketone) (P3)}

A solution of P1 $(0.1 \mathrm{~g})$ and 4- $n$-octylbenzoic acid $(0.32 \mathrm{~g})$ in PPMA $(3 \mathrm{ml})$ was heated at $90^{\circ} \mathrm{C}$ for $6 \mathrm{~h}$. The resulting solution was poured into water $(300 \mathrm{ml})$. The precipitate was filtered, and washed with water and methanol, and reprecipitated from THF into methanol to give $\mathbf{P 3}$ (0.11 g, 62\%).

\subsection{Preparation of hyperbranched poly(ether ketone) (P4)}

A solution of P1 $(0.1 \mathrm{~g})$ and stearic acid $(0.47 \mathrm{~g})$ in PPMA $(4 \mathrm{ml})$ was heated at $90^{\circ} \mathrm{C}$ for $6 \mathrm{~h}$. The resulting solution was poured into water $(300 \mathrm{ml})$. The precipitate was filtered and washed with water and acetone. The polymer was dissolved in hot toluene $(100 \mathrm{ml})$. The solution was then concentrated to $2 \mathrm{ml}$, and precipitated into acetone to give $\mathbf{P 4}(0.12 \mathrm{~g}, 64 \%)$.

\section{Results and discussion}

\subsection{Synthesis and characterization of the hyperbranched poly(ether ketone) (P1)}

The $\mathrm{AB}_{2}$ monomer 3,5-diphenoxybenzoic acid, 2, was prepared by either reacting phenol with 5-dibromotoluene or reacting 5-methylresorcinol with bromobenzene via the Ullmann reaction to form compound $\mathbf{1}[44,45]$, followed by oxidation of the methyl group of $\mathbf{1}$ with $\mathrm{KMnO}_{4}$ [46], as outlined in Scheme 1. The general procedure developed by Ueda for the preparation of linear aromatic poly(ether ketone)s [40-42] was applied to the one-step polymerization of the $\mathrm{AB}_{2}$ monomer. The synthesis of poly(ether ketone) is based on the electrophilic aromatic substitution, in which an aryl ketone linkage is formed by condensing an carboxylic group with an activated phenyl group. In this synthetic procedure, PPMA was used as the condensing agent and solvent [43]. PPMA is expected to react with the carboxylic acid group to yield a highly activated mixed anhydride intermediate between the carboxylic acid and methanesulfonic acid and enable condensation to proceed under rather mild reaction conditions. To demonstrate the feasibility of using this reaction for the formation 
Table 1

Polymerization of 3,5-diphenoxybenzoic acid in PPMA

\begin{tabular}{lrlrrr}
\hline Temperature $\left({ }^{\circ} \mathrm{C}\right)$ & Time $(\mathrm{h})$ & $M_{\mathrm{w}}{ }^{\mathrm{a}}$ & $M_{\mathrm{n}}{ }^{\mathrm{a}}$ & $M_{\mathrm{w}} / M_{\mathrm{n}}$ & $T_{\mathrm{g}}\left({ }^{\circ} \mathrm{C}\right)$ \\
\hline 90 & 6 & 20180 & 4890 & 4.12 & 150 \\
90 & 12 & 31990 & 5750 & 5.58 & 159 \\
90 & 24 & 59460 & 6740 & 8.82 & 168 \\
110 & 6 & 98500 & 7710 & 12.78 & 180 \\
\hline
\end{tabular}

${ }^{\text {a }}$ SEC in DMF solutions calibrated against poly(ethylene glycol) standards.

of hyperbranched poly(ether ketones), the reaction of benzoic acid with the bis-phenoxy groups of monomer $\mathbf{2}$ in PPMA was chosen as the model reaction for the polymerization of $\mathbf{2}$. The carboxylic group of $\mathbf{2}$ was initially protected as a methyl ester group to give compound $\mathbf{3}$, which was then reacted with an excess of benzoic acid. The model reaction proceeded at $80^{\circ} \mathrm{C}$ in PPMA and yielded compound 4 quantitatively after $4 \mathrm{~h}$. In the acylated product 4, the two benzoyl groups were exclusively at the para position of the bis-phenoxy groups, as analyzed by NMR spectroscopy. The model reaction revealed that the acylation had taken place clearly at the para position. Based on the model study it seems apparent that the electrophilic aromatic substitution of $\mathbf{2}$ occurs in the yield and selectivity required for a polymer forming reaction.

The one-step polymerization of $\mathbf{2}$ was performed in PPMA to give the corresponding hyperbranched poly(ether ketone), P1. The structure of $\mathbf{P 1}$ and the general reaction are shown in Scheme 2. The IR spectrum of $\mathbf{P 1}$ exhibits characteristic absorptions at 1664 and $1212 \mathrm{~cm}^{-1}$ corresponding to the $\mathrm{C}=\mathrm{O}$ and $\mathrm{C}-\mathrm{O}-\mathrm{C}$ stretching. As predicted theoretically by Flory [47], the direct polymerization of $\mathrm{AB}_{2}$ type monomers would produce polymers with a highly branched, irregular structure, which prevents close packing and crystallization of various polymer segments. The hyperbranched P1 was found to be highly soluble in a variety of solvents such as $\mathrm{CHCl}_{3}, \mathrm{CH}_{2} \mathrm{Cl}_{2}, \mathrm{THF}$, DMF, and NMP. The enhanced solubility of $\mathbf{P 1}$ when compared to that of linear

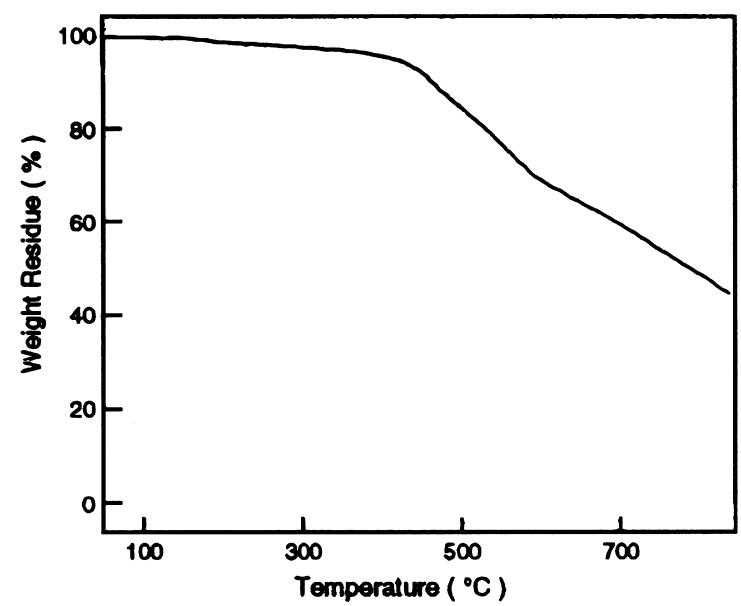

Fig. 1. TGA thermogram of hyperbranched poly(ether ketone) $\mathbf{P 1}$.

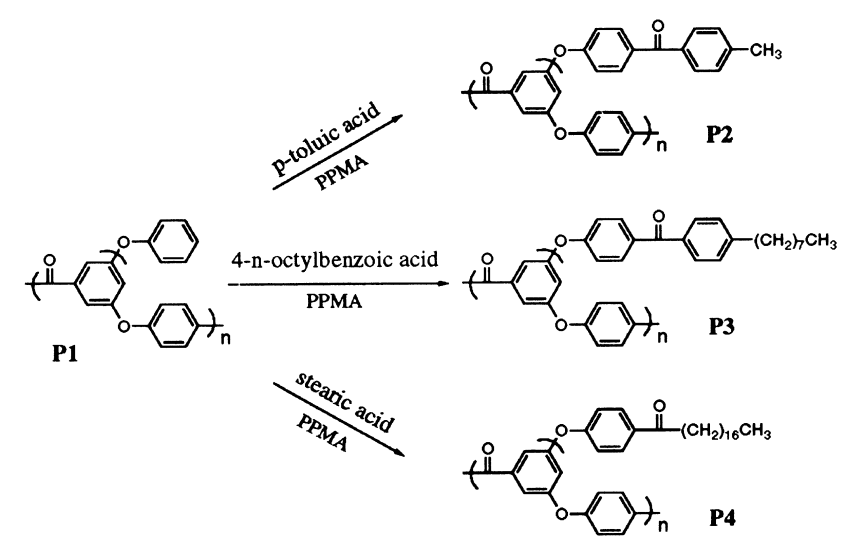

Scheme 3.

poly(ether ketone)s is consistent with the highly branched structure of $\mathbf{P 1}$ and is in agreement with similar results obtained for other hyperbranched macromolecules [35]. Unlike dendritic macromolecules, which are essentially perfectly branched, hyperbranched macromolecules have a much more irregular structure. The concept of the degree of branching was introduced to better define the structure of the hyperbranched polymers [9]. In the $\mathrm{AB}_{2}$ systems such as 1,3,5-substituted benzene, the degree of branching determined by NMR is usually about $50 \%-60 \%[8,17-19,24]$. However, for the hyperbranched poly(ether ketone) P1, the degree of branching could not be determined from its ${ }^{1} \mathrm{H}$ NMR spectrum because the chemical shifts of the aromatic protons were not well resolved for this determination.

The molecular weight of the hyperbranched poly(ether ketone) was determined by SEC analysis in DMF solutions calibrated against poly(ethylene glycol) standards, and used only for a rough estimate. It was noted that SEC measurements, in which linear polymer standards were used to determine molecular masses for highly branched polymers, tended to underestimate the true molecular weight of the hyperbranched polymers [48]. The molecular weight of the resulting polymer was sensitive to the reaction time and the reaction temperature. As seen in Table 1, samples with a broad range of molecular weights were prepared. The molecular weight distribution of these poly(ether ketones) is broad, and broader than that of hyperbranched poly(ether ketones) prepared by nucleophilic substitution [35]. As the molecular weight increases, the molecular weight distribution becomes broader. This observation resembles previous reports of other hyperbranched polymers $[18,24,32]$ and is consistent with the predictions of Flory [47].

The glass transition temperature $\left(T_{\mathrm{g}}\right)$ of the hyperbranched poly(ether ketone) was determined by DSC. $T_{\mathrm{g}}$ of P1, which was observed to increase modestly with molecular weight, ranged from $150^{\circ} \mathrm{C}$ to $180^{\circ} \mathrm{C}$, as shown in Table 1. The thermal stability of $\mathbf{P 1}$ was examined by TGA. A typical trace for polymer $\mathbf{P 1}$ is shown in Fig. 1. The polymer is stable up to $400^{\circ} \mathrm{C}$, with a $10 \%$ weight loss occurring over $460^{\circ} \mathrm{C}$. This result indicates that the thermal 
Table 2

Effect of the functionality of the chain ends on the thermal and solution properties of the hyperbranched poly(ether ketones)

\begin{tabular}{|c|c|c|c|c|c|c|c|c|}
\hline \multirow[t]{2}{*}{ Polymer } & \multirow[t]{2}{*}{$T_{\mathrm{g}}\left({ }^{\circ} \mathrm{C}\right)$} & \multicolumn{7}{|c|}{ Solubility $^{\mathrm{a}}$} \\
\hline & & Octane & Toluene & $\mathrm{CH}_{2} \mathrm{Cl}_{2}$ & $\mathrm{CHCl}_{3}$ & THF & DMF & NMP \\
\hline P1 & 150 & - & - & + & + & + & + & + \\
\hline P2 & & - & - & + & + & + & + & + \\
\hline P3 & 16 & - & \pm & + & + & + & + & + \\
\hline P4 & -24 & \pm & \pm & \pm & \pm & \pm & - & - \\
\hline
\end{tabular}

${ }^{\text {a }}$ Solubility: + , soluble; \pm , partially soluble; - , insoluble.

stability of the hyperbranched poly(ether ketone) $\mathbf{P 1}$ is comparable to that of the linear analog [40-42].

\subsection{Chemical modification of hyperbranched poly(ether ketones) (P1)}

Hyperbranched polymers based on $\mathrm{AB}_{2}$ monomers are characterized by a large number of chain end groups, the number of which is equal to the degree of polymerization plus one. The terminal phenoxy groups in $\mathbf{P 1}$ are active toward electrophilic substitution and readily react with carboxylic acids to form aryl ketone linkages. As shown in Scheme 3, alkyl groups with different chain length could be introduced into the terminal positions of P1 by reacting the terminated phenoxy groups with a variety of carboxylic acids using PPMA as the condensing agent and solvent. The degree of functionalization of the derivatized polymers was estimated by comparing ${ }^{1} \mathrm{H}$ NMR integration of the alkyl peaks with that of the aromatic peaks. For $\mathbf{P 2}$ and P3, the ${ }^{1} \mathrm{H}$ NMR analysis showed that the functionalization was almost completed ( $>95 \%$ ), indicating the phenoxy groups at the chain ends of $\mathbf{P 1}$ are readily accessible to reagents in solution. For P4, ${ }^{1} \mathrm{H}$ NMR analysis in solvents such as $\mathrm{CDCl}_{3}$ and $\operatorname{THF}\left(\mathrm{D}_{4}\right)$ revealed an interesting solution state behavior. The aromatic peaks become obscure owing to the significant broadening of their ${ }^{1} \mathrm{H}$ NMR

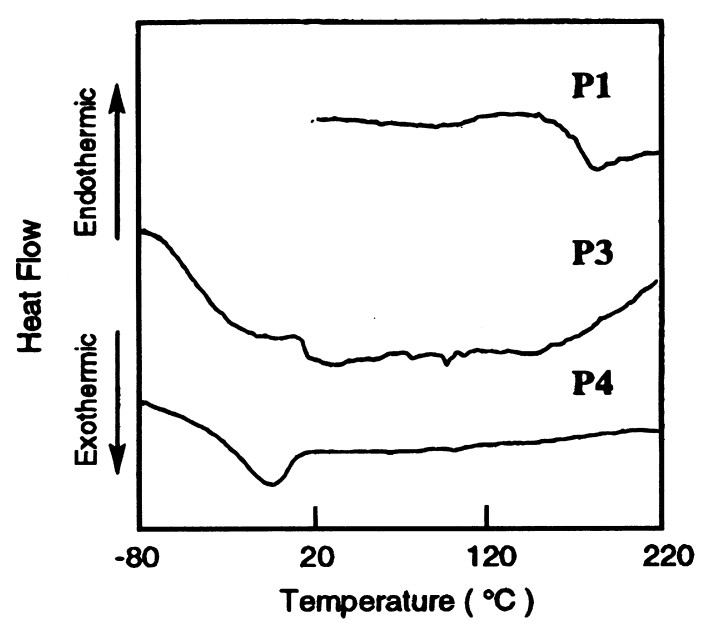

Fig. 2. DSC thermograms of hyperbranched poly(ether ketones) P1, P3 and P4. resonances and only the resonances associated with the heptadecyl group at the chain ends were observed. This spectroscopic observation may be attributed to the formation of aggregates in solution, with the more polar dendritric poly(ether ketone) block likely to be situated at the core and surrounded by the nonpolar, long linear alkyl chains. The aggregation might significantly increase the relaxation times for the aromatic protons of the confined aryl-etherketone blocks and lead to the broadening of their ${ }^{1} \mathrm{H}$ NMR resonances. Similarly spectroscopic phenomena was observed in dendritic-linear block copolymers [49]. Further, the ratio of the ${ }^{1} \mathrm{H}$ NMR integration of the alkyl peaks to that of the aromatic peaks is about twice larger than expected if the convertion of the formation of $\mathbf{P 4}$ is $100 \%$. This may result from the broadening of ${ }^{1} \mathrm{H}$ NMR resonances caused by the aggregation or from the contamination of unreacted stearic acid in P4. Nevertheless, the latter possibility can be easily ruled out by DSC experiments. For a sample of $\mathbf{P 4}$ mixed with 0.1 equivalent of stearic acid, in addition to the endothermic curve corresponding to the glass transition of the polymer, an endothermic peak arising from the melt of stearic acid was also observed. A sample containing P4 only, however, did not show any melting point in the DSC thermogram. Therefore, we conclude that the smaller than expected integration for the aromatic protons may also be attributed to the broadening of their ${ }^{1} \mathrm{H}$ NMR resonances resulting from the aggregation.

It was shown that the nature of the chain ends markedly affects properties such as the glass transition temperature $\left(T_{\mathrm{g}}\right)$ and the solubility of hyperbranched polymer (Table 2) [29-36, 50-52]. As shown in Fig. 2, the $T_{g}$ s determined by DSC of these poly(ether ketones) heavily depend on the chain length of the terminal alkyl groups, with decreases in $T_{\mathrm{g}}$ following increases in alkyl chain length. On going from $\mathbf{P 1}$, to an octyl end group, $\mathbf{P 3}$, the glass transition temperature of the hyperbranched poly(ether ketones) drops from $150^{\circ} \mathrm{C}$ to $16^{\circ} \mathrm{C}$. A further decrease in $T_{\mathrm{g}}$ to $-24^{\circ} \mathrm{C}$ is observed for the polymer $\mathbf{P 4}$ with heptadecyl end groups. Attempts were made to measure the $T_{\mathrm{g}}$ of $\mathbf{P} 2$. However, between $0^{\circ} \mathrm{C}$ and $300^{\circ} \mathrm{C}$, no reliable endotherm corresponding to the glass transition of $\mathbf{P 2}$ was observed.

As a result of the lack of crystalline packing and complexation of the solvent in the cavities, the hyperbranched poly(ether ketone) has an enhanced 
solubility in organic solvents. P1 and P2 are highly soluble in typical solvents such as $\mathrm{CH}_{2} \mathrm{Cl}_{2}$, THF, DMF and NMP. However, the different chain ends led to differences in solubility in polar and nonpolar solvents. An increase in the chain length of the terminal alkyl groups implies a reduction in the solubility of the polymer in polar solvents, resulting in a situation in which P4 is insoluble in DMF. Conversely, the linear alkyl chains help impart solubility in nonpolar solvents. Although P1 and P2 are totally insoluble in nonpolar solvents, P3 and P4 are soluble in toluene and P4 is partially soluble in octane.

\section{Summary}

A hyperbranched poly(ether ketone) was conveniently prepared by the self-condensation of an $\mathrm{AB}_{2}$ monomer, 3,5-diphenoxybenzoic acid, using PPMA as the condensing agent and solvent. This one-step synthesis involved electrophilic aromatic substitution, resulting in the formation of the ketone linkage. The phenoxy groups at the chain ends of the hyperbranched poly(ether ketone) are highly reactive for further electrophilic aromatic substitution and readily reacted with various carboxylic acids. In addition, the nature of the chain ends markedly affects the physical properties such as glass transition temperature and solubility of the modified hyperbranched poly(ether ketones). As the length of the terminal alkyl groups increase, the $T_{\mathrm{g}}$ of the polymer decreases, and the solubility of the polymer in polar solvents is reduced, becoming more soluble in nonpolar solvents.

\section{Acknowledgements}

We would like to thank the National Science Council (ROC) (NSC 87-2113-M009-003) for financial support.

\section{References}

[1] Newkome GR. Advances in dendritic molecules, 1. Greenwich, CT: JAI Press, 1994.

[2] Newkome GR, Moorefield CN, Vögtle F. Dendritic molecules: concepts, syntheses, perspectives. New York: VCH Publishers, 1996.

[3] Tomalia DA, Baker H, Dewald J, Hall M, Kallos G, Martin S, Roeck J, Ryder J, Smith P. Polym J 1985;17:117.

[4] Newkome GR, Yao Z, Baker GR, Gupta VK. J Org Chem 1985;50:2004.

[5] Hawker CJ, Frechet JMJ. J Am Chem Soc 1990;112:7638.

[6] Wooley KL, Hawker CJ, Frechet JMJ. J Am Chem Soc 1991;113:4252.

[7] Wolley KL, Fréchet JMJ, Hawker CJ. Polymer 1994;35:4489.
[8] Kim YH, Webster OW. J Am Chem Soc 1990;112:4592.

[9] Hawker CJ, Lee R, Fréchet JMJ. J Am Chem Soc 1991;113:4583.

[10] Mathias LJ, Carothers TWJ. Am Chem Soc 1991;113:4043.

[11] Percec V, Kawsum M. Macromolecules 1992;25:7071.

[12] Suzuki M, Ii A, Saegusa T. Macromolecules 1992;25:7071.

[13] Spindler R, Fréchet JMJ. Macromolecules 1993;26:4809.

[14] Chu F, Hawker CJ. Polym Bull 1993;30:265.

[15] Johansson M, Malmström E, Hult A. J Polym Sci: Polym Chem 1993;31:619.

[16] Miller TM, Neenan TX, Kwock EW, Stein SM. J Am Chem Soc 1993;115:356.

[17] Kumar A, Ramakrishnan S. J Chem Soc Chem Commun 1993;1453.

[18] Turner SR, Walter F, Voit BI, Mourey TH. Macromolecules 1994;27:1611.

[19] Feast WJ, Stainton NM. J Mater Chem 1995;5:405.

[20] Jin R-H, Andou Y. Macromolecules 1996;29:8010.

[21] Srinivasan S, Twieg R, Hedrick JL, Hawker CJ. Macromolecules 1996;29:8543.

[22] Hedrick JL, Hawker CJ, Miller RD, Twieg R, Srinivasan SA, Trollsas M. Macromolecules 1997;30:7607.

[23] Bharathi P, Moore JS. J Am Chem Soc 1997;119:3391.

[24] Feast WJ, Keeney AJ, Kenwright AM, Parker D. J Chem Soc Chem Commun 1997:1749.

[25] Mueller A, Kowalewski T, Wooley KL. Macromolecules 1998;31:776

[26] Lach C, Frey H. Macromolecules 1998;31:2381.

[27] Spetseris N, Ward RE, Meye TY. Macromolecules 1998;31:3158.

[28] Tao XT, Zhang Y-D, Wada T, Sasabe H, Susuki H, Watanabe T, Miyata S. Adv Mater 1998;10:226.

[29] Uhrich KE, Hawker CJ, Frechet JMJ, Turner SR. Macromolecules 1992;25:4583.

[30] Kim YH, Webster OW. Macromolecules 1992;25:5561.

[31] Kim YH. J Am Chem Soc 1992;114:4947.

[32] Turner SR, Voit BI, Mourey TH. Macromolecules 1993;26:4617.

[33] Wooley KL, Hawker CJ, Lee R, Fréchet JMJ. Polym J 1994;26:187.

[34] Malmström E, Johansson M, Hult A. Macromolecules 1995;28:1698.

[35] Hawker CJ, Chu F. Macromolecules 1996;29:4370.

[36] Bolton DH, Wooley KL. Macromolecules 1997;30:1890.

[37] Attwood YE, Dawson PC, Freeman JL, Hoy LR, Rose JB, Staniland PA. Polymer 1981;22:1096.

[38] Litter MI, Marvel CS. J Polym Sci Polym Chem ed 1985;23:2205.

[39] Morikawa A, Kakimoto M, Imai Y. Macromolecules 1993;26:6324.

[40] Ueda M, Kano T. Makromol Chem, Rapid Commun 1985;5:833.

[41] Ueda M, Kano T, Waragai T, Sugita H. Makromol Chem, Rapid Commun 1985;6:847.

[42] Ueda M, Sato M. Macromolecules 1987;20:2675.

[43] Eaton PE, Carlson GR, Lee JT. J Org Chem 1973;38:4071.

[44] Ueda M, Toyoda H, Nakayama T, Abe T. J Polym Sci Polym Chem 1996;34:109.

[45] Williams AL, Kinney RE, Bridger RF. J Org Chem 1967;328:2501.

[46] Ungnade HE. J Am Chem Soc 1941;63:2091.

[47] Flory PJ. J Am Chem Soc 1952;74:2718.

[48] Hawker CJ, Fréchet JMJ. J Chem Soc Chem Soc Chem Commun 1990:1010.

[49] Leduc MR, Hayes W, Frechet JMJ. J Polym Sci Polym Chem ed 1998;36:1.

[50] Kim YH. Adv Mater 1992;4:11

[51] Kim YH, Beckerbauer R. Macromolecules 1994;27:1968.

[52] Fréchet JMJ, Menmi M, Gitsov I, Aoshima S, Leduc M R, Grubbs RB. Science 1995;269:1080. 